УДК 61

DOI $10.21661 / \mathrm{r}-117894$

М.М. Хабибулина, А.Н. Дмитриев, Н.Н. Федорова

БЕЗБОЛЕВАЯ ИШЕМИЯ МИОКАРДА У ЖЕНЩИН

С АРТЕРИАЛЬНОЙ ГИПЕРТЕНЗИЕЙ С ГИПОЭСТРОГЕНИЕЙ

В ПОЗДНЕМ ФЕРТИЛЬНОМ ВОЗРАСТЕ С «МЕТАБОЛИЧЕСКИ ЗДОРОВЫМ» ВИСЦЕРАЛЬНЫМ ОЖИРЕНИЕМ

Аннотация: в статье изложены результаты холтер-мониторирования ЭКГ у 78 женщин с АГ ІІ стадии в позднем фертильном периоде с диагностированной гипертрофией миокарда левого желудочка с гипоэстрогенемией с «метаболически здоровым» висиеральным ожирением (МЗВО) на амбулаторном этапе и частота выявления эпизодов ББИМ у данной категории больных. Пациентки с АГ с концентрической ГМЛЖ имеют большую потенциальную возможность развития относительной коронарной недостаточности, чем женщиныс с ее эксиентрическим вариантом. Ограничение коронарной перфузии и снижение релаксационных свойств гипертрофированного миокарда у женщин с АГв позднем фертильном периоде с диагностированной ГМЛЖ может являться патофизиологической основой механизма ишемии миокарда, проявляющейся в виде эпизодов ББИМ, которая достоверно чаще $(p<0,05)$ встречается у больных $c$ метаболически «нездоровым» ожирением.

Ключевые слова: безболевая ишемия миокарда, артериальная гипертензия, поздний фертильный период, дислипидемия, метаболически здоровое ожирение.

M.M. Khabibulina, A.N. Dmitriev, N.N. Fedorova

\title{
SILENT MYOCARDIAL ISCHEMIA IN WOMEN WITH ARTERIAL HYPERTENSION WITH HYPESTROGENISM IN THE LATE FERTILE PERIOD WITH "METABOLICALLY HEALTHY" VISCERAL OBESITY
}

Abstract: the article contains the results of holter ECG monitoring of 78 women with arterial hypertension of the II stage in the late fertile period with diagnosed left 
ventricular hypertrophy with hypoestrogenemy with "metabolically healthy" visceral obesity (MHVO) at the outpatient stage and the frequency of episodes of SMI in this category of patients. Patients with hypertension with concentric LVH have a greater potential for the development of relative coronary insufficiency, than women with its eccentric option. Limitation of coronary perfusion and reduced relaxation properties of hypertrophied myocardium in women with hypertension in late fertile period with diagnosed LVH may be a pathophysiological basis of the mechanism of myocardial ischemia, which is manifested in the form of episodes of SMI, which is significantly more often $(p<0,05)$ occurs in patients with metabolic "morbid"obesity.

Keywords: silent myocardial ischemia, arterial hypertension, late fertile period, dyslipidemia, "metabolically healthy" obesity.

В условиях гормонального дисбаланса происходят изменения в организме женщины: повышается уровень артериального давления, развивается гипертрофия миокарда левого желудочка (ГМЛЖ), безболевая ишемия миокарда (ББИМ) $[1-3]$.

В настоящее время у исследователей вызывает интерес особый фенотип заболевания, получивший название «метаболически здоровое ожирение» (МЗО) [4]. Однако отсутствием единых дефиниций объясняется также крайняя вариабельность данных о распространенности МЗО и его естественном течении.

В 2013 г. группой европейских экспертов с целью стандартизации биомедицинских исследовательских баз данных была создана программа BioSHaRE-EU (Biobank Standardization and Harmonization for Research Excellence in the European Union) [5]. Первой научной разработкой программы стал проект по M3О (Healthy Obese Project). В этом проекте к метаболически здоровым отнесены пациенты с ожирением (ИМТ от 30 кг/мІ и более), имеющие не более одного из 6 факторов кардиометаболического риска - повышения показателей артериального давления, уровней триглицеридов, гликемии натощак, СРБ, снижения липопротеинов высокой плотности и чувствительности к инсулину. 
Целью исследования явилось изучение ББИМ у женщин с АГ в позднем репродуктивном периоде с диагностированной гипертрофией миокарда левого желудочка с гипоэстрогенемией с метаболически здоровым ожирением.

Дизайн исследования: В исследование были включены 78 женщин с АГ III ст. (Верификация диагноза АГ проводилась в соответствии с Российскими рекомендациями по профилактике, диагностике и лечению артериальной гипертензии (2013г.) с гипоэстрогенемией, имеющих, по данным эхокардиографического исследования ГМЛЖ.

Критерии исключения: ИБС, инсульт, сахарный диабет, реноваскулярная патология. Всем женщинам выполнялась ЭхоКГ и 24-часовое Холтер- мониторирование ЭКГ, АД по стандартным методикам.

Все женщины были разделены на две группы: в первую группу вошли 40 женщин с АГ с дефицитом эстрадиола с МЗО. В группы сравнения были включены метаболически «нездоровые» больные ожирением 38 женщин с АГ с дефицитом эстрадиола с дислипидемией. Характеристика пациенток, составивших клинические группы представлена в таблице.

Таблица

Характеристика пацченток, составивиих клинические группь

\begin{tabular}{|l|c|c|c|}
\hline \multicolumn{1}{|c|}{ Параметры } & Группа 1 & Группа II & Р1-2 \\
\hline Возраст, годы & $46,01 \pm 2,17$ & $47,11 \pm 2,4$ & Н. д. \\
\hline Эстрадиол, пкг/мл & $0,42 \pm 0,05$ & $0,37 \pm 0,07$ & Н. д. \\
\hline ФСГ, МЕ/ мл & $12,89 \pm 0,42$ & $13,74 \pm 1,64$ & Н. д. \\
\hline САД ср, мм. рт. ст. & $138,2 \pm 14,75$ & $139,1 \pm 12,88$ & Н. д. \\
ДАД ср, мм. рт. ст. & $86,9 \pm 11,8$ & $84,21 \pm 9,15$ & Н. д. \\
\hline Длительность АГ, годы & $4,7 \pm 1,7$ & $5,1 \pm 1,8$ & Н.д. \\
\hline Индекс массы, кг/м² & $30,2 \pm 1,9$ & $32,4 \pm 1,8$ & $<0,05$ \\
\hline ОХС, ммоль/л & $4,3 \pm 0,5$ & $5,47 \pm 0,90$ & $<0,05$ \\
\hline ХСЛПНП, ммоль/л & $3,3 \pm 0,6$ & $4,1 \pm 0,8$ & $<0,05$ \\
\hline ХСЛПВП, моль/л & $1,39 \pm 0,7$ & $1,31 \pm 0,37$ & $<0,05$ \\
\hline ТГ, моль/л & $0,74 \pm 0,8$ & $1,79 \pm 0,85$ & $<0,05$ \\
\hline КА & $2,1 \pm 0,5$ & $3,2 \pm 1,4$ & $<0,05$ \\
\hline
\end{tabular}

Pезультаты: При сопоставимой продолжительности АГ и практически равнозначных значениях у женщин обеих групп, имеющих концентрическую 
ГМЛЖ, таких показателей, как индекс массы миокарда левого желудочка, толщина межжелудочковой перегородки и задней стенки левого желудочка в диастолу, а также показателей диастолической функции левого желудочка, больные 2-й группы имели достоверно большие размеры и объемы левого желудочка ( $\mathrm{p}<0,05)$. Ишемия миокарда, проявляющаяся в виде эпизодов ББИМ достоверно чаще ( $\mathrm{p}<0,05)$ встречалась у женщин второй группы с метаболически «нездоровым» ожирением. При анализе частоты появления эпизодов ББИМ у женщин с АГ в обеих группах в зависимости от варианта ГМЛЖ установлено, что ББИМ у пациенток 1-й группы с МЗО достоверно чаще регистрировалась у лиц с концентрической ГМЛЖ, имеющих большие значения ИММЛЖ и более выраженные изменения внутрисердечной гемодинамики, чем с ее эксцентрическим вариантом - в 21,6\% и 8,6\% соответственно. При этом ББИМ у пациенток с концентрической ГМЛЖ имела большие значения среднесуточной частоты и продолжительности эпизодов, чем у лиц с ее эксцентрическим вариантом. У женщин 2-ой группы эпизоды ББИМ выявлялись достаточно часто как среди пациенток с эксцентрической ГМЛЖ, так и концентрической - 27,2\% и 31,1\% соответственно, но так же как у пациенток 1-й группы с МЗО характеризовались тенденцией к увеличению основных параметров ББИМ у женщин с концентрической ГМЛЖ, имеющих более выраженные изменения в морфофункциональном состоянии левого желудочка при этом варианте ГМЛЖ. Вместе с тем, основные параметры ББИМ у пациенток с метаболически «нездоровым» ожирением, независимо от варианта ГМЛЖ, имели большие значения, чем у лиц 1-й группы с МЗО с соответствующими типами ГМЛЖ. Таким образом, пациентки с АГ с концентрической ГМЛЖ имеют большую потенциальную возможность развития относительной коронарной недостаточности, чем женщины с ее эксцентрическим вариантом. Ограничение коронарной перфузии и снижение релаксационных свойств гипертрофированного миокарда у женщин с АГ в позднем фертильном периоде с диагностированной ГМЛЖ, может являться патофизиологической ос- 
новой механизма ишемии миокарда, проявляющейся в виде эпизодов ББИМ, которая достоверно чаще ( $<$ 0,05) встречается у больных с дислипидемией с метаболически «нездоровым» ожирением.

\section{Сиисок литературы}

1. Хабибулина М.M. Структурно-геометрические изменения левых отделов сердца, систолическая и диастолическая дисфункция у женщин с артериальной гипертензией в позднем фертильном периоде и период пременопаузы // Кардиология и сердечно-сосудистая хирургия. - 2009. - №2. - С. 75-78.

2. Хабибулина М.М. Опыт выявления ББИМ у женщин с гипертонической болезнью в период пременопаузы на амбулаторном этапе / M.М. Хабибулина, А.Н. Андреев, И.Ф. Гришина, Р.В. Серебренников // Сибирский медицинский журнал. - 2010. - Т. 25. - №2. - С. 160-163.

3. Хабибулина М.М. Сравнительный анализ особенностей сердечно-болевого синдрома и безболевая ишемия миокарда у женщин с артериальной гипертензией в период пременопаузы в зависимости от суточного профиля артериального давления / М.М. Хабибулина // Кардиология и сердечно-сосудистая хирургия. - 2011. - №3. - С. 55-60.

4. Alam I, Ng TP, Larbi A. Does inflammation determine whether obesity is metabolically healthy or unhealthy? The aging perspective. Mediators Inflamm. 2012; 2012: 456456.

5. Vliet-Ostaptchouk JV, Nuotio ML, Slagter SN The prevalence of metabolic syndrome and metabolically healthy obesity in Europe: a collaborative analysis of ten large cohort studies. BMC Endocr Disord. 2014; 14: 9. 
Хабибулина Марина Михайловна - канд. мед. наук, доцент кафедры поликлинической терапии, ультразвуковой и функциональной диагностики ГБОУ ВО «Уральский государственный медицинский университет» Минздрава России; МБУ «Екатеринбургский консультативно-диагностический центр», Россия, Екатеринбург.

Khabibulina Marina Mikhailovna - candidate of medical sciences, associate professor of the department of Polyclinical Therapy, Ultrasonic and Functional Diagnosis SBEI of HE "Ural State Medical University" of The Ministry of Healthcare of Russian Federation; MBI “Ekaterinburg Consultation and Diagnostic Center”, Russia, Ekaterinburg.

Дмитриев Анатолий Николаевич - д-р мед. наук, профессор кафедры факультетской терапии и эндокринологии ГБОУ ВО «Уральский государственный медицинский университет» Минздрава России, Россия, Екатеринбург.

Dmitriev Anatoly Nikolaevich - doctor of medical sciences, professor of the Department of Faculty Therapy and Endocrinology SBEI of HE "Ural State Medical University" of The Ministry of Healthcare of Russian Federation, Russia, Ekaterinburg.

Федорова Наталья Николаевна - врач-терапевт ГБУЗ СО «Свердловская областная клиническая больница №1», Россия, Екатеринбург.

Fedorova Natalia Nikolaevich - general practitioner "Sverdlovsk Regional Clinical Hospital №1”, Russia, Ekaterinburg. 